\title{
Associations in physical activity and sedentary behaviour among the immigrant and non-immigrant US population
}

\author{
Heontae Kim, ${ }^{1}$ Chao Cao, ${ }^{2}$ Igor Grabovac (D, ${ }^{3}$ Guillermo F López Sánchez (D, ${ }^{4}$ \\ Benny Rana, ${ }^{5}$ Louis Jacob, ${ }^{6,7}$ Ai Koyanagi, ${ }^{7,8}$ Nicola Veronese, ${ }^{9}$ Lin Yang, ${ }^{5,10}$ \\ Lee Smith ${ }^{11}$
}

For numbered affiliations see end of article.

\section{Correspondence to}

Dr Guillermo F López Sánchez, Faculty of Sport Sciences, University of Murcia, Murcia 30720, Spain; gfls@um.es and Dr Lee Smith, The Cambridge Centre for Sport and Exercise Sciences, Anglia Ruskin University, Cambridge CB1 1BT, UK:

Lee.Smith@anglia.ac.uk

Received 5 January 2020 Revised 6 March 2020 Accepted 7 April 2020

\section{Check for updates}

(c) Author(s) (or their employer(s)) 2020. No commercial re-use. See rights and permissions. Published by BMJ.

To cite: Kim H, Cao C, Grabovac I, et al. J Epidemiol Community Health 2020;74:655-661.

\begin{abstract}
Background Immigrants are at a higher risk of poor mental and physical health. Regular participation in physical activity (PA) and low levels of sedentary time are beneficial for both these aspects of health. The aim was to investigate levels and trends in domain-specific PA and sedentary behaviour in the US. immigrant compared with non-immigrant populations.
\end{abstract}

Methods From the 2007-2016 National Health and Nutrition Examination Survey (NHANES), a total of 25142 adults ( $\geq 18$ years) were included in this analysis. PA and sedentary behaviour time were assessed by a questionnaire.

Results Transit-related PA showed downward linear trends in young immigrant adults $\left(p_{\text {trend }}=0.006\right)$ and middle-aged non-immigrant adults ( $p_{\text {trend }}=0.009$ ). We found significant upward linear trends in sedentary behaviour for both immigrants and non-immigrants across all age groups. For sitting watching TV or videos $\geq 2$ hours/day, there was a downward linear trend in young immigrant adults $\left(p_{\text {trend }}=0.009\right)$. For computer use $\geq 1$ hours/day, an upward linear trend in older nonimmigrants was found ( $p_{\text {trend }}=0.024$ ). Young immigrants spent $37.5(95 \% \mathrm{Cl}-55.4$ to -19.6$)$ min less than nonimmigrants on recreational PA per week. Also, older immigrants spent 23.5 (95\% Cl 1.5 to 45.6$)$ and 22.5 (95\% Cl 5.9 to 39.0 ) min/week more than nonimmigrants on recreational PA and transit-related PA, respectively. Last, young and middle-aged immigrants spent $37.6(95 \% \mathrm{Cl}-68.2$ to -7.0$)$ and $37.6(95 \% \mathrm{Cl}$ -99.7 to -9.7$) \mathrm{min} /$ day less than non-immigrants on sedentary behaviour, respectively.

Conclusion Overall, levels of recreational PA were stable, yet the transit-related PA declined coupled with an increase in sedentary behaviour. US. immigrants exhibit higher levels of transit-PA, lower levels of leisure-time PA and lower levels of sedentary behaviour, in some age groups.

\section{INTRODUCTION}

An immigrant is a person who comes to live permanently in a foreign country. The US has more immigrants than any other country worldwide. Since 1965, when US immigration laws replaced a national quota system, the number of immigrants living in the US more than quadrupled. Immigrants today account for $13.6 \%$ of the US population, nearly triple that observed $(4.7 \%)$ in $1970 .{ }^{1}$ Importantly, a large body of literature suggests that immigrants are at a higher risk of poor mental health including schizophrenia and related disorders, ${ }^{2}$ mood disorders ${ }^{3}$ and, among women, postpartum depressive symptoms. ${ }^{4}$ Immigration may be detrimental to mental health because it may be associated with a 'culture shock' and with greater physical distances from family and friend support networks. ${ }^{5} 6$

The majority of immigrants tend to have a lower socioeconomic status (SES). This is likely owing to underemployment, ${ }^{7}$ discrimination ${ }^{8}$ and financial and social barriers. ${ }^{9}$ Importantly, lower SES is associated with poorer health, greater morbidity and a higher risk of mortality. ${ }^{10-13}$ In support, it has been shown that in the US, recent immigrants experienced the largest cardiovascular health declines over time: immigrants living in the US $<10$ years at baseline experienced a greater decline in the Cardiovascular Health Score $(-1.04,95 \%$ CI -1.27 to -0.80 ) over 10 years compared with those who were US born $(-0.47,95 \%$ CI -0.52 to $-0.42) .{ }^{14}$ Moreover, a lower SES is also associated with lower levels of physical activity (PA). ${ }^{15}$

Importantly, the participation (or not) in health behaviours either positively or negatively influences both mental and physical health, such that regular participation in recreational or transportation PA (one health behaviour) is beneficial for almost every facet of mental and physical health. ${ }^{16}$ Conversely, high levels of sedentary time are detrimental to most aspects of health. ${ }^{17}$ Population levels of PA are generally low ${ }^{18} 19$ and sedentary behaviour high, particularly in the US. ${ }^{20}$ It is possible that low levels of PA and high levels of sedentary time are partly driving the higher prevalence of poor mental and physical health among immigrant populations. A study conducted on 784 cancer patients found that immigrants were less likely to be aware of and benefited from PA participation. ${ }^{21}$ In a large Canadian study carried out over a decade ago, it was shown that immigrants exhibited relatively low levels of leisure-time PA. ${ }^{22}$ In another Canadian study, recent and established immigrants were more likely to have an active commute, but a lower likelihood of walking, sports, endurance, and recreation activities than non-immigrants. ${ }^{23} \mathrm{To}$ our knowledge, no literature exists on levels of PA or sedentary behaviour among the US immigrant population. It is important to understand such levels to inform novel avenues for intervention to improve the mental and physical health of the US immigrant population. 
The aim of the present study was to investigate the trends and patterns of domain-specific PA and sedentary behaviour in the US immigrant compared with non-immigrant populations.

\section{MATERIALS AND METHODS \\ Study population}

Data were extracted from the five cycles of the 2007-2016 National Health and Nutrition Examination Survey (NHANES). Data were released in 2-year cycles (eg, 2007-2008 and 2009-2010). The NHANES is a cross-sectional study that applies a complex, multistage, stratified, clustered probability design to assess the health and nutritional status of the US civilian noninstitutionalised population. The NHANES protocol was approved by the review board of the National Center for Health Statistics Ethics. All participants provided written consent to participate in the survey. In the present study, age groups were defined as young (18-35 years), middle-aged (36-55 years) and older adults (>55 years). ${ }^{24}$ We extracted data on sociodemographic information, and PA and sedentary behaviour and the variables were combined into a single dataset for each data cycle from the 2007-2008 to 2015-2016 cycles.

\section{Immigration status}

Immigration status was assessed using the following question: 'In what country were you born?' Response options included 'born in 50 US States or Washington, DC', 'born in Mexico', 'born in other Spanish-speaking country' and 'born in other non-Spanishspeaking country'. If participants were born in 50 US States or Washington, DC, they were classified as non-immigrants. If participants were born in Mexico, other Spanish-speaking country, or other non-Spanish-speaking country, they were classified as immigrants.

\section{Physical activity and sedentary behaviour measures}

PA and sedentary behaviour measures were based on the Global Physical Activity Questionnaire (GPAQ) developed by the WHO for PA surveillance. ${ }^{25}$

Self-reported recreational or transit-related PA included a series of questions. The questions included typical frequency and duration of PA performed during transportation and leisure activities. Weekly recreational PA was assessed using the following questions: (1) 'In a typical week, how many days do you do vigorous-intensity (or moderate-intensity) sport, fitness or recreational activities' and (2) 'How much time do you spend doing vigorous-intensity (or moderate-intensity) sport, fitness or recreational activities on a typical day?' Weekly transit-related PA was assessed using the following questions: (1) 'In a typical week, how many days do you walk or bicycle for at least $10 \mathrm{~min}$ continuously to get to and from places' and (2) 'How much time do you spend walking or bicycling for travel on a typical day?' Weekly recreational PA was calculated by adding reported minutes (ie, frequency $\times$ duration) of moderate PA to minutes of vigorous PA, then converted to hours for the ease of interpretation. Daily sedentary behaviour, including time spent sitting at a desk, travelling in a car or bus, reading, playing cards, watching television or using a computer, was measured using a single question: 'How much time do you usually spend sitting on a typical day?' Screen-based sedentary behaviours (eg, watching TV or videos, using a computer or play computer) were assessed using following two questions: (1) 'Over the past 30 days, on average, how many hours per day did you sit and watch television or videos?' and (2) 'Over the past 30 days, on average, about how many hours per day did you use a computer or play computer games outside of school or work', with options of none, less than 1 hour, 1 hour, 2 hours, 4 hours or 5 hours or more per day. For primary analyses, participants' responses were recategorised into $\geq 2$ hours per day and $<2$ hours per day for sitting watching television and $\geq 1$ hour per day and $<1$ hour per day for computer use. These cut-offs have been used, as well as approximated median values, in previous studies. ${ }^{26} 27$ Data for sitting watching television and computer use were available only in the 2011-2016 cycle.

\section{Covariate variables}

Self-reported sociodemographic characteristics included age, sex (male, female), race/ethnicity (non-Hispanic white, Mexican American, other Hispanic, non-Hispanic black, other race), household income $(<\$ 25000, \$ 25000-\$ 45000,>\$ 45000$ $\$ 75000,>\$ 75000)$, education level (some high school or less, high school graduate, some college, college graduate or above), work status (currently working or not) and occupational PA as control variables. These covariates were selected because they were hypothesised to be associated with both the exposure and outcome $e^{728}$ and available within the NHANES dataset.

\section{Statistical analysis}

All statistical analyses were performed using SURVEY analysis procedures in SAS version 9.4 (SAS institute INC., Cary, North Carolina) to account for the sample weights, stratification and clustering of the complex nature of the NHANES sampling scheme. Participants' descriptive characteristics by immigration status were analysed for each subgroup as mean and frequency using SURVEYMEANS and SURVEYFREQ procedures, respectively. Mean weekly recreational and transit-related PA time and daily sedentary behaviour time were calculated by years. Tests for linear trends were performed to examine trends of each PA time and sedentary behaviour by the cycles using orthogonal polynomial coefficients. Multivariable linear regression was used to examine the association between immigration status and PA and sedentary behaviour using the pooled sample, including all participants of all cycles. We estimated the association of immigration status with recreational PA, transit-related PA and sedentary behaviour. For adjusted models, age, sex, race/ethnicity, income, education level, work status and NHANES year cycles were controlled for. Statistical significance was set a priori at $\mathrm{p}$ value $<0.05$.

\section{RESULTS}

A total of 30587 men and women aged $\geq 18$ years provided data on PA, sedentary behaviour and immigration status. A total of 5445 participants were excluded due to missing covariates, leaving a total of 25142 in the final analyses. Overall, 16.8\% of the participants were immigrants. Unweighted sample size and weighted percentage in the 2015-2016 cycle are presented in table 1 (data not shown for occupational PA). In this sample, the average age of immigrants and non-immigrants was 44.7 $(\mathrm{SE}=0.4 ; 49.0 \%$ men) and 47.8 (SE=0.3; 47.4\% men), respectively.

Table 2 displays the secular trends in weighted mean hours of recreational PA per week across the NHANES cycles from 2007-2008 to 2015-2016. We did not find a significant trend in immigrant or non-immigrant participants by age group. For transit-related PA (table 3), there were downward linear trends in young immigrant adults $\left(p_{\text {trend }}=0.006\right)$ and middle-aged nonimmigrant adults $\left(p_{\text {trend }}=0.009\right)$. Table 4 indicates trends in weighted mean hours of sedentary behaviour per day. We found 
Table 1 Participant characteristics of the National Health and Nutrition Examination Survey Study in 2015-2016

\begin{tabular}{|c|c|c|c|c|}
\hline & $\begin{array}{l}\text { Immigrant } \\
(\mathrm{n}=1572)\end{array}$ & & $\begin{array}{l}\text { Non-immigrant } \\
(n=3216)\end{array}$ & \\
\hline \multirow[t]{2}{*}{ Age (years) (SE) } & $44.7(0.4)$ & & $47.8(0.3)$ & \\
\hline & $\mathrm{N}$ & $\%$ & $\mathrm{~N}$ & $\%$ \\
\hline $18-35$ & 396 & 31.2 & 924 & 28.9 \\
\hline $36-55$ & 630 & 43.5 & 1014 & 35.0 \\
\hline$>55$ & 546 & 25.3 & 1278 & 36.1 \\
\hline \multicolumn{5}{|l|}{ Sex } \\
\hline Men & 753 & 49.0 & 1540 & 47.4 \\
\hline Women & 819 & 51.0 & 1676 & 52.6 \\
\hline \multicolumn{5}{|l|}{ Race } \\
\hline Mexican American & 433 & 25.3 & 374 & 4.8 \\
\hline Other Hispanic & 403 & 21.4 & 210 & 2.7 \\
\hline Non-Hispanic White & 76 & 14.5 & 1558 & 76.3 \\
\hline Non-Hispanic Black & 133 & 8.6 & 877 & 11.6 \\
\hline Other Race & 527 & 30.3 & 197 & 4.5 \\
\hline \multicolumn{5}{|l|}{ Household income } \\
\hline$<\$ 25000$ & 493 & 26.7 & 815 & 15.3 \\
\hline$\$ 25000-\$ 45000$ & 360 & 21.9 & 718 & 18.2 \\
\hline$>\$ 45000-\$ 75000$ & 306 & 19.6 & 725 & 23.4 \\
\hline$>\$ 75000$ & 413 & 31.8 & 958 & 43.1 \\
\hline \multicolumn{5}{|l|}{ Education } \\
\hline Some high school or less & 603 & 32.0 & 491 & 9.9 \\
\hline High school graduate & 242 & 15.3 & 806 & 22.1 \\
\hline Some college & 316 & 22.3 & 1124 & 34.5 \\
\hline College graduate or above & 411 & 30.3 & 795 & 33.6 \\
\hline \multicolumn{5}{|l|}{ Working status } \\
\hline Yes & 960 & 65.3 & 1852 & 64.5 \\
\hline No & 612 & 34.7 & 1364 & 35.5 \\
\hline
\end{tabular}

All estimates were weighted to be nationally representative of the US population.

significant upward linear trends in sedentary behaviour for both immigrants and non-immigrants across all age groups.

Table 5 shows trends in screen-based sedentary behaviour (eg, sitting watching TV or videos, computer use). For sitting watching TV or videos $\geq 2$ hours per day, there were downward linear trends in young immigrant adults $\left(p_{\text {trend }}=0.009\right)$. For computer use $\geq 1$ hours per day, an upward linear trend in older nonimmigrants was found ( $\left.p_{\text {trend }}=0.024\right)$.

Table 6 includes crude and adjusted differences in recreational PA, transit-related PA and sedentary behaviour between immigrants and non-immigrants according to age across all study cycles. In the crude model, young (18-35 years) and middle-aged (36-55 years) immigrants spent 45.8 (95\% CI -64.8 to -26.9$)$ and $17.2(95 \%$ CI -33.6 to -0.7$)$ min less than non-immigrants on recreational PA per week, respectively. Middle-aged and older immigrants spent 34.2 (95\% CI 12.6 to 55.8) and 30.6 (95\% CI 13.2 to 47.9) $\mathrm{min} /$ week more than non-immigrants on transit-related PA. Also, in all age groups, immigrants spent less than non-immigrants on sedentary behaviour.

In the adjusted model (ie, controlling for age, sex, race/ethnicity, household income, education level, work status, occupational PA and NHANES year cycles), young immigrants spent 37.5 (95\% CI -55.4 to -19.6$)$ min less than non-immigrants on recreational PA per week. Also, older immigrants spent 23.5 (95\% CI 1.5 to 45.6 ) and 22.5 (95\% CI 5.9 to 39.0 ) $\mathrm{min} /$ week more than non-immigrants on recreational PA and transit-related PA, respectively. Last, young and middle-aged immigrants spent $37.6(95 \%$ CI -68.2 to -7.0$)$ and $37.6(95 \%$ CI -99.7 to -9.7$)$ $\mathrm{min} /$ day less than non-immigrants on sedentary behaviour, respectively.

\section{DISCUSSION}

In this large representative sample of the US population, it was found that $16.8 \%$ of participants were immigrants. Over a period of 8 years, levels of sedentary behaviour increased in both immigrants and non-immigrants. Based on the multivariable regression analysis, it was found that young immigrants between 18 and 35 years spent less time than non-immigrants in recreational PA. Whereas, immigrants older than 55 years spent greater time on transit-related (ie, active travel) and occupational PA than non-immigrants. Finally, for the first time, the present study found that immigrants' aged between 18 and 55 years spent less time in sedentary behaviour than their nonimmigrant counterparts.

Findings from the present study support the limited literature in this area. Similar to this study, others have found lower levels of leisure-time PA in immigrant populations compared with

Table 2 Age-specific trends in weighted mean recreational physical activity (hour/week) in the National Health and Nutrition Examination Survey study from 2007 to 2008 to 2015-2016

\begin{tabular}{|c|c|c|c|c|c|c|c|c|}
\hline & & \multicolumn{5}{|l|}{ Year } & \multirow[b]{2}{*}{$p_{\text {trend }}$ for linear } & \multirow{2}{*}{$\begin{array}{l}\text { Difference between first } \\
\text { and last cycle }\end{array}$} \\
\hline & & $2007-2008$ & 2009-2010 & 2011-2012 & 2013-2014 & 2015-2016 & & \\
\hline \multirow[t]{3}{*}{18 to 35 years } & Overall & 3.1 (2.7 to 3.5 ) & 3.1 (2.7 to 3.4 ) & 3.7 (3.0 to 4.4$)$ & 3.2 (2.7 to 3.7 ) & 3.5 (3.1 to 3.8 ) & 0.145 & $0.4(-0.1$ to 0.9$)$ \\
\hline & Immigrant & 2.4 (1.8 to 3.1$)$ & 2.6 (2.1 to 3.2$)$ & 2.8 (2.0 to 3.7 ) & 2.6 (2.2 to 3.0$)$ & 2.9 (2.5 to 3.2$)$ & 0.273 & $0.5(-0.2$ to 1.2$)$ \\
\hline & Non-immigrant & 3.3 (2.8 to 3.7 ) & 3.2 (2.7 to 3.6 ) & 3.9 (3.1 to 4.6$)$ & 3.3 (2.8 to 3.9 ) & 3.6 (3.2 to 4.0$)$ & 0.211 & $0.3(-0.3$ to 0.9$)$ \\
\hline \multirow[t]{3}{*}{36 to 55 years } & Overall & 2.3 (1.9 to 2.7$)$ & 2.4 (2.2 to 2.7$)$ & 2.7 (2.3 to 3.1$)$ & 2.5 (2.2 to 2.7$)$ & 2.7 (2.2 to 3.1$)$ & 0.162 & $0.4(-0.2$ to 1.0$)$ \\
\hline & Immigrant & 2.1 (1.6 to 2.6$)$ & 2.2 (1.6 to 2.7$)$ & 2.3 (1.9 to 2.7$)$ & 2.6 (2.1 to 3.1$)$ & 2.2 (1.8 to 2.6$)$ & 0.387 & $0.1(-0.5$ to 0.7$)$ \\
\hline & Non-immigrant & 2.3 (1.8 to 2.8 ) & 2.5 (2.2 to 2.8$)$ & 2.8 (2.3 to 3.2 ) & 2.4 (2.2 to 2.7$)$ & 2.8 (2.2 to 3.3 ) & 0.199 & $0.5(-0.2$ to 1.2$)$ \\
\hline \multirow[t]{3}{*}{$>55$ years } & Overall & $1.8(1.5$ to 2.0$)$ & 1.9 (1.6 to 2.2$)$ & 2.0 (1.7 to 2.4$)$ & 1.9 (1.5 to 2.3$)$ & 2.0 (1.7 to 2.3$)$ & 0.273 & $0.2(-0.2$ to 0.6$)$ \\
\hline & Immigrant & 1.9 (0.9 to 2.9$)$ & 2.1 (1.4 to 2.8 ) & 1.8 (1.1 to 2.4$)$ & 1.9 (1.3 to 2.5$)$ & 2.0 (1.6 to 2.3 ) & 0.952 & $0.1(-0.9$ to 1.1$)$ \\
\hline & Non-immigrant & $1.7(1.5$ to 2.0$)$ & 1.9 (1.6 to 2.2$)$ & 2.1 (1.7 to 2.4$)$ & 1.9 (1.5 to 2.3$)$ & 2.0 (1.6 to 2.4$)$ & 0.270 & $0.3(-0.2$ to 0.8$)$ \\
\hline
\end{tabular}

All estimates were weighted to be nationally representative of the US population; values in parentheses were Cls. 
Table 3 Age-specific trend in weighted mean transit-related physical activity (walk/bicycle, hours/week) in the National Health and Nutrition Examination Survey study from 2007 to 2008 to 2015-2016

\begin{tabular}{|c|c|c|c|c|c|c|c|c|}
\hline & & \multicolumn{5}{|l|}{ Year } & \multirow[b]{2}{*}{$p_{\text {trend }}$ for linear } & \multirow{2}{*}{$\begin{array}{l}\text { Difference between } \\
\text { first and last cycle }\end{array}$} \\
\hline & & 2007-2008 & 2009-2010 & 2011-2012 & 2013-2014 & 2015-2016 & & \\
\hline \multirow[t]{3}{*}{18 to 35 years } & Overall & 1.9 (1.3 to 2.5$)$ & $1.5(1.2$ to 1.7$)$ & 2.2 (1.4 to 2.9$)$ & $1.6(1.1$ to 2.0$)$ & $1.2(1.0$ to 1.4$)$ & 0.042 & $-0.7(-1.3$ to -0.1$)$ \\
\hline & Immigrant & 2.1 (1.1 to 3.0$)$ & 2.2 (1.5 to 2.9$)$ & 2.2 (1.5 to 3.0$)$ & 1.3 (0.9 to 1.8$)$ & $1.0(0.7$ to 1.3$)$ & 0.006 & $-1.1(-2.0$ to -0.2$)$ \\
\hline & Non-immigrant & 1.8 (1.2 to 2.4$)$ & $1.3(1.1$ to 1.5$)$ & 2.2 (1.3 to 3.0$)$ & $1.6(1.1$ to 2.1$)$ & $1.2(1.0$ to 1.4$)$ & 0.167 & $-0.6(-1.2$ to 0.1$)$ \\
\hline \multirow[t]{3}{*}{36 to 55 years } & Overall & 1.4 (1.0 to 1.9$)$ & $1.4(1.1$ to 1.8$)$ & $1.6(1.2$ to 1.9$)$ & $1.0(0.8$ to 1.2$)$ & 0.9 (0.6 to 1.2$)$ & 0.005 & $-0.5(-1.1$ to 0.1$)$ \\
\hline & Immigrant & 2.2 (0.9 to 3.5$)$ & $2.0(1.4$ to 2.5$)$ & 1.9 (1.2 to 2.6$)$ & 1.3 (0.6 to 1.9$)$ & $1.4(0.8$ to 1.9$)$ & 0.104 & $-0.8(-2.1$ to 0.5$)$ \\
\hline & Non-immigrant & 1.3 (0.9 to 1.7$)$ & 1.3 (0.9 to 1.7$)$ & 1.5 (1.1 to 1.9$)$ & 0.9 (0.7 to 1.2$)$ & 0.7 (0.4 to 1.1$)$ & 0.009 & $-0.6(-1.1$ to -0.1$)$ \\
\hline \multirow[t]{3}{*}{$>55$ years } & Overall & 0.9 (0.6 to 1.1$)$ & 0.7 (0.5 to 0.8$)$ & 1.3 (0.9 to 1.6$)$ & $0.8(0.6$ to 0.9$)$ & 0.7 (0.4 to 0.9$)$ & 0.488 & $-0.2(-0.6$ to 0.2$)$ \\
\hline & Immigrant & $1.6(0.5$ to 2.6$)$ & $0.8(0.5$ to 1.0$)$ & $2.0(1.1$ to 2.9$)$ & $1.1(0.7$ to 1.5$)$ & $1.2(0.6$ to 1.7$)$ & 0.720 & $-0.4(-1.5$ to 0.7$)$ \\
\hline & Non-immigrant & 0.8 (0.5 to 1.1$)$ & $0.6(0.4$ to 0.8$)$ & 1.2 (0.8 to 1.5$)$ & 0.7 (0.6 to 0.8$)$ & 0.6 (0.4 to 0.8$)$ & 0.469 & $-0.2(-0.6$ to 0.2$)$ \\
\hline
\end{tabular}

All estimates were weighted to be nationally representative of the US population; values in parentheses were Cls.

Table 4 Age-specific trends in weighted mean total sitting time (hours/day) in the National Health and Nutrition Examination Survey study from 2007 to 2008 to $2015-2016$

\begin{tabular}{|c|c|c|c|c|c|c|c|c|}
\hline & & \multicolumn{5}{|l|}{ Year } & \multirow[b]{2}{*}{$p_{\text {trend }}$ for linear } & \multirow{2}{*}{$\begin{array}{l}\text { Difference between first } \\
\text { and last cycle }\end{array}$} \\
\hline & & 2007-2008 & 2009-2010 & 2011-2012 & 2013-2014 & 2015-2016 & & \\
\hline \multirow[t]{3}{*}{18 to 35 years } & Overall & 5.4 (5.0 to 5.7$)$ & 5.8 (5.5 to 6.0$)$ & 6.4 (6.0 to 6.7$)$ & 7.1 (6.7 to 7.5$)$ & 6.9 (6.4 to 7.5$)$ & $<0.001$ & 1.5 (0.8 to 2.2$)$ \\
\hline & Immigrant & 4.6 (4.1 to 5.1$)$ & 5.1 (4.4 to 5.7 ) & 5.6 (5.0 to 6.3$)$ & 6.6 (5.9 to 7.2 ) & 6.6 (5.2 to 8.1$)$ & 0.001 & 2.0 (0.4 to 3.6$)$ \\
\hline & Non-immigrant & 5.5 (5.2 to 5.9$)$ & 5.9 (5.7 to 6.2$)$ & 6.5 (6.2 to 6.9$)$ & 7.2 (6.7 to 7.7 ) & 7.0 (6.3 to 7.7$)$ & $<0.001$ & 1.5 (0.7 to 2.3$)$ \\
\hline \multirow[t]{3}{*}{36 to 55 years } & Overall & 5.6 (5.2 to 5.9$)$ & 6.0 (5.6 to 6.3 ) & 6.4 (6.1 to 6.8$)$ & 7.4 (6.9 to 8.0$)$ & 7.3 (6.6 to 8.0$)$ & $<0.001$ & 1.7 (0.9 to 2.5$)$ \\
\hline & Immigrant & 4.3 (3.5 to 5.1$)$ & 5.1 (4.1 to 6.1 ) & 5.6 (4.8 to 6.5 ) & 6.3 (5.9 to 6.6 ) & 6.0 (5.1 to 6.9$)$ & 0.001 & $1.7(0.5$ to 2.9$)$ \\
\hline & Non-immigrant & 5.9 (5.6 to 6.2$)$ & 6.2 (5.9 to 6.5 ) & 6.6 (6.3 to 6.9$)$ & 7.7 (7.1 to 8.3$)$ & 7.6 (6.8 to 8.4 ) & $<0.001$ & $1.7(0.9$ to 2.5$)$ \\
\hline \multirow[t]{3}{*}{$>55$ years } & Overall & 6.5 (5.7 to 7.3 ) & 6.2 (5.8 to 6.7 ) & 7.0 (6.5 to 7.5$)$ & 7.8 (7.4 to 8.2 ) & 7.6 (6.8 to 8.4 ) & 0.001 & $1.1(-0.1$ to 2.2$)$ \\
\hline & Immigrant & 5.3 (4.1 to 6.4 ) & 6.1 (4.3 to 7.9 ) & 5.8 (4.9 to 6.7$)$ & 7.0 (6.0 to 8.0$)$ & 7.4 (5.4 to 9.3 ) & 0.033 & $2.1(-0.4$ to 4.6$)$ \\
\hline & Non-immigrant & 6.6 (5.7 to 7.6$)$ & 6.3 (5.8 to 6.7$)$ & 7.2 (6.6 to 7.7 ) & 7.9 (7.5 to 8.4$)$ & 7.7 (6.8 to 8.5$)$ & 0.004 & $1.1(-0.2$ to 2.4$)$ \\
\hline
\end{tabular}

All estimates were weighted to be nationally representative of the US population; values in parentheses were Cls.

non-immigrants. ${ }^{23}$ Several factors may explain the observed association. First, previous literature has suggested that immigrants are less aware of the benefits of regular participation in $\mathrm{PA},{ }^{21}$ and being less knowledgeable of the benefits of PA is a shown risk factor for lower levels of PA. ${ }^{29}$ Next, immigrants are likely to be from a lower SES, ${ }^{13}$ and a lower SES is associated with lower levels of $\mathrm{PA}^{15}$ likely owing to a lesser importance placed on this behaviour. In previous literature, immigrants reported higher levels of discrimination, ${ }^{30}$ and such discrimination may prevent immigrants from participating in leisure-time PA where they may be required to integrate/mix with natives, such as a sport clubs or exercise classes. Finally, we speculate that time constraint may contribute to the lack of opportunities for leisure-time PA among immigrants as well. Although little data are available specifically among immigrant populations, time constraints have shown to negatively impact leisure-time PA such as sports participation. ${ }^{31}$ 'Too busy' is a term used among US migrant workers that prevents them to access healthcare. ${ }^{32}$ Likewise, time constraints may pose even stronger barriers for their leisure-time PA participation.

The present study found higher levels of transit PA among older immigrants. This finding supports that of the only other study to investigate domain-specific PA among immigrants. ${ }^{21}$ It may be that immigrants do not have access to personal automated transport likely owing to cost and SES. Indeed, in the US, ethnic minorities (a proxy for immigrant status) are less likely to own cars. ${ }^{33}$ While the present study found lower levels of leisure-time PA in the younger age (18-35 years) immigrant US population, higher levels of leisure-time PA were found in the older age (>55 years) immigrant population compared with the nonimmigrant population, after adjusting for a range of covariates including occupational PA. It is possible that the working-age immigrants may compensate heavy occupational PA with less time spent in leisure-time PA. Indeed, immigrants are more likely to undertake manual occupations than non-immigrants. ${ }^{34}$

For the first time, the present study has shown that levels of sedentary behaviour in young and middle-aged immigrants are lower than that of non-immigrants. Immigrants tend to perform worse in education than non-immigrants, particularly in subjects such as science. ${ }^{35}$ Therefore, it may be that natives are spending greater time in homework-type activities that are by nature sedentary. Owing to the fact that immigrants are more likely to be from a lower SES, ${ }^{13}$ it is also possible that they are less likely to have game consoles, tablets and computers and thus have less opportunity to engage in sedentary behaviour. However, these hypotheses remain untested, and future work of a qualitative nature to identify potential mechanisms is now required. Interestingly, observed lower levels of sedentary behaviour among immigrant populations may partly explain the immigrant mortality paradox where immigrants experience greater longevity. ${ }^{13} 3637$ Indeed, higher levels of sedentary time have been shown to be associated with early all-cause mortality. ${ }^{38}$ 
Table 5 Trend in weighted percentage of sitting watching TV or videos $\geq 2$ hours per day and computer use outside school or work $\geq 1$ hour per day Year 2011-2012 2013-2014 2015-2016 $\quad p_{\text {trend }}$ for linear Difference between first and last cycle

\begin{tabular}{|c|c|c|c|c|c|c|}
\hline \multicolumn{7}{|c|}{ Sitting watching TV or videos $\geq 2$ hours per day, weighted $\%(95 \% \mathrm{Cl})$} \\
\hline \multirow[t]{3}{*}{18 to 35 years } & Overall & $61.8(55.6$ to 68.0$)$ & $61.9(59.4$ to 64.5$)$ & $57.2(54.0$ to 60.3$)$ & 0.193 & $-4.6(-11.5$ to 2.3$)$ \\
\hline & Immigrant & $63.6(58.4$ to 68.9$)$ & $54.3(48.4$ to 60.2$)$ & 52.5 (46.3 to 58.8$)$ & 0.009 & $-11.1(-19.5$ to -2.7$)$ \\
\hline & Non-immigrant & $61.3(54.1$ to 68.5$)$ & $63.4(60.8$ to 66.0$)$ & $58.2(55.0$ to 61.5$)$ & 0.438 & $-3.1(-11.1$ to 4.9$)$ \\
\hline \multirow[t]{3}{*}{36 to 55 years } & Overall & $62.2(58.6$ to 65.9$)$ & $63.9(60.4$ to 67.3$)$ & $61.9(56.9$ to 66.9$)$ & 0.913 & $-0.3(-6.4$ to 5.8$)$ \\
\hline & Immigrant & 52.1 (46.2 to 53.8$)$ & $51.8(45.1$ to 58.5$)$ & $46.3(42.0$ to 50.6$)$ & 0.117 & $-5.8(-11.7$ to 0.1$)$ \\
\hline & Non-immigrant & $64.8(60.9$ to 68.8$)$ & $67.0(63.3$ to 70.6$)$ & $66.0(59.6$ to 72.5$)$ & 0.752 & $1.2(-6.1$ to 8.5$)$ \\
\hline \multirow[t]{3}{*}{$>55$ years } & Overall & 79.7 (76.7 to 82.7$)$ & 81.1 (78.1 to 84.2$)$ & 83.5 (80.4 to 86.7$)$ & 0.083 & $3.8(-0.6$ to 8.2$)$ \\
\hline & Immigrant & $67.9(61.9$ to 73.9$)$ & $65.9(59.9$ to 71.8$)$ & $69.2(62.7$ to 75.8$)$ & 0.767 & $1.3(-7.9$ to 10.5$)$ \\
\hline & Non-immigrant & $81.2(77.9$ to 84.5$)$ & 83.4 (80.1 to 86.7$)$ & 85.7 (82.3 to 89.1$)$ & 0.066 & $4.5(-0.3$ to 9.3$)$ \\
\hline \multicolumn{7}{|c|}{ Computer use outside school or work $\geq 1$ hour per day, weighted $\%(95 \% \mathrm{Cl})$} \\
\hline \multirow[t]{3}{*}{18 to 35 years } & Overall & $63.9(59.0$ to 68.7$)$ & $55.3(52.2$ to 58.4$)$ & $56.6(51.2$ to 62.0$)$ & 0.049 & $-7.3(-14.6$ to -0.1$)$ \\
\hline & Immigrant & 58.9 (48.1 to 69.8$)$ & $53.8(47.5$ to 60.1$)$ & 47.2 (38.9 to 55.5$)$ & 0.089 & $-11.7(-25.2$ to 1.8$)$ \\
\hline & Non-immigrant & $65.0(60.2$ to 69.8$)$ & 55.6 (52.0 to 59.2 ) & 58.7 (53.0 to 64.4$)$ & 0.096 & $-6.3(-13.7$ to 1.1$)$ \\
\hline \multirow[t]{3}{*}{36 to 55 years } & Overall & 46.7 (43.4 to 49.9$)$ & 47.5 (43.8 to 56.2 ) & 48.8 (46.2 to 51.5$)$ & 0.308 & $2.1(-2.1$ to 6.3$)$ \\
\hline & Immigrant & 43.1 (38.0 to 48.3$)$ & 38.4 (33.6 to 43.2 ) & 40.8 (36.2 to 45.5$)$ & 0.504 & $-2.3(-9.3$ to 4.7$)$ \\
\hline & Non-immigrant & 47.6 (43.5 to 51.7$)$ & 49.9 (45.8 to 54.0$)$ & $51.0(48.0$ to 53.9$)$ & 0.181 & 3.4 (-1.9 to 8.7$)$ \\
\hline \multirow[t]{3}{*}{$>55$ years } & Overall & 40.3 (35.4 to 45.2$)$ & 44.2 (40.0 to 48.5 ) & 48.1 (43.7 to 52.5 ) & 0.021 & 7.8 (1.1 to 14.5$)$ \\
\hline & Immigrant & 27.9 (20.7 to 35.1$)$ & 33.9 (27.5 to 40.2$)$ & 34.9 (27.3 to 42.6$)$ & 0.183 & 7.0 (-3.8 to 17.8$)$ \\
\hline & Non-immigrant & 41.9 (36.6 to 47.1$)$ & $45.8(41.5$ to 50.0$)$ & 50.1 (45.3 to 54.9$)$ & 0.024 & 8.2 (0.9 to 15.5$)$ \\
\hline
\end{tabular}

All estimates were weighted to be nationally representative of the US population; values in parentheses were Cls.

It should be noted that the present study found mixed findings on generation differences, for example, only finding higher levels of transit PA in older immigrants. Reasons behind this generational difference are not currently clear, and further research to tease out explanations for these nuances are now required.

Clear strengths of the present study include the large representative sample of the US adult population and the investigation of domain-specific PA levels and sedentary behaviour by immigration status in the US population for the first time. However, the findings from the study should be interpreted in light of its limitations. First, PA was self-reported, thus introducing reporting bias, but such self-report tools allow for the measuring of domain-specific PA on a population scale. Second, the data are of cross-sectional nature, and thus it is not known whether leisuretime PA levels of immigrants were low before they entered the
US. Finally, no data were available on age at immigration or whether participants have immigrants as parents this would have allowed for a more nuanced analysis.

\section{CONCLUSION}

In conclusion, the present study found that US immigrants exhibit higher levels of transit PA, lower levels of leisure-time PA and lower levels of sedentary behaviour, in some but not all age groups. These findings should be considered when designing interventions to improve the health and well-being of the US immigrant population. Future work is needed to shed light on the underlying mechanisms driving the observed associations. In addition, future studies should investigate the role of immigrant status in the association of PA and sedentary behaviour with health-related outcomes.

Table 6 Beta coefficients of the association of immigrant status with recreational and transit-related physical activity (PA) and sedentary behaviour from the linear regression models

\begin{tabular}{|c|c|c|c|c|c|c|c|}
\hline & & \multicolumn{2}{|l|}{18 to 35 years } & \multicolumn{2}{|l|}{36 to 55 years } & \multicolumn{2}{|l|}{$>55$ years } \\
\hline & & Unadjusted & Adjusted & Unadjusted & Adjusted & Unadjusted & Adjusted \\
\hline \multirow[t]{2}{*}{ Recreational PA } & Non-immigrant & Reference & & Reference & & Reference & \\
\hline & Immigrant & $\begin{array}{l}-45.8^{*} \\
(-64.8 \text { to }-26.9)\end{array}$ & $\begin{array}{l}-37.5^{*} \\
(-55.4 \text { to }-19.6)\end{array}$ & $\begin{array}{l}-17.2^{*} \\
(-33.6 \text { to }-0.7)\end{array}$ & $\begin{array}{l}10.1 \\
(-11.2 \text { to } 31.5)\end{array}$ & $\begin{array}{l}-0.1 \\
(-18.1 \text { to } 17.9)\end{array}$ & $\begin{array}{l}23.5^{*} \\
(1.5 \text { to } 45.6)\end{array}$ \\
\hline \multirow[t]{2}{*}{ Transit-related PA } & Non-immigrant & Reference & & Reference & & Reference & \\
\hline & Immigrant & $\begin{array}{l}8.8 \\
(-12.2 \text { to } 29.9)\end{array}$ & $\begin{array}{l}6.0 \\
(-13.6 \text { to } 25.6)\end{array}$ & $\begin{array}{l}34.2^{*} \\
(12.6 \text { to } 55.8)\end{array}$ & $\begin{array}{l}13.6 \\
(-14.8 \text { to } 41.9)\end{array}$ & $\begin{array}{l}30.6^{*} \\
(13.2 \text { to } 47.9)\end{array}$ & $\begin{array}{l}22.5^{*} \\
\text { (5.9 to } 39.0 \text { ) }\end{array}$ \\
\hline \multirow[t]{2}{*}{ Sedentary behaviour } & Non-immigrant & Reference & & Reference & & Reference & \\
\hline & Immigrant & $\begin{array}{l}-46.1^{*} \\
(-72.3 \text { to }-20.0)\end{array}$ & $\begin{array}{l}-37.6^{*} \\
(-68.2 \text { to }-7.0)\end{array}$ & $\begin{array}{l}-78.7^{*} \\
(-101.7 \text { to }-55.8)\end{array}$ & $\begin{array}{l}-54.7^{*} \\
(-99.7 \text { to }-9.7)\end{array}$ & $\begin{array}{l}-45.8^{*} \\
(-86.6 \text { to }-4.9)\end{array}$ & $\begin{array}{l}-27.5 \\
(-79.6 \text { to } 24.7)\end{array}$ \\
\hline
\end{tabular}

adjusted: beta coefficient when controlling for age, gender, race/ethnicity, education level, income, occupational physical activity and NHANES year cycles; PA, physical activity; unadjusted, crude beta coefficient; units are minutes per week for physical activity and per day for sedentary behaviour; values in parentheses were $\mathrm{Cls}$; ${ }^{*}<0.05$. 


\section{What is already known on this subject}

- A large body of literature suggests that immigrants are at a higher risk of poor mental health and poor cardiovascular health.

- The participation (or not) in health behaviours either positively or negatively influences both mental and physical health.

- No literature exists on levels of physical activity or sedentary behaviour among the US.immigrant population.

\section{What this study adds}

- Levels of sedentary behaviour increased regardless of immigration status.

- US immigrants exhibit higher levels of transit-related physical activity, lower levels of leisure-time physical activity and lower levels of sedentary behaviour, in some but not all age groups.

- These findings should be considered when designing interventions to improve the health and well-being of the US immigrant population.

\author{
Author affiliations \\ ${ }^{1}$ Research and Analytics Laboratory, School of Applied Sciences, University of \\ Mississippi, University Park, Mississippi, USA \\ ${ }^{2}$ Program in Physical Therapy, Washington University School of Medicine, St Louis, \\ Missouri, USA \\ ${ }^{3}$ Department of Social and Preventive Medicine, Center for Public Health, Medical \\ University of Vienna, Vienna, Austria \\ ${ }^{4}$ Faculty of Sport Sciences, University of Murcia, Murcia, Spain \\ ${ }^{5}$ Department of Cancer Epidemiology and Prevention Research, Cancer Control \\ Alberta, Alberta Health Services, Calgary, Canada \\ ${ }^{6}$ Faculty of Medicine, University of Versailles Saint-Quentin-en-Yvelines, Montigny-le- \\ Bretonneux, France \\ ${ }^{7}$ Research and Development Unit, Parc Sanitari Sant Joan De Déu, CIBERSAM, \\ Barcelona, Spain \\ ${ }^{8}$ ICREA, Pg. Lluis Companys 23, Barcelona, Spain \\ ${ }^{9}$ Azienda ULSS 3 Serenissima, Primary Care Department, Venice, Italy \\ ${ }^{10}$ Deparmtents of Oncology and Community Health Sciences, University of Calgary, \\ Calgary, Canada \\ ${ }^{11}$ The Cambridge Centre for Sport and Exercise Sciences, Anglia Ruskin University, \\ Cambridge, UK
}

Contributors All authors (HK, CC, IG, GFLS, BR, LJ, AK, NV, LY, LS) contributed planning, writing and revising this article. All authors are responsible for the overall content of this paper.

Funding The authors have not declared a specific grant for this research from any funding agency in the public, commercial or not-for-profit sectors.

Competing interests None declared.

Patient consent for publication Not required.

Data sharing statement All data relevant to the study are included in the article or uploaded as supplementary information.

Provenance and peer review Not commissioned; externally peer reviewed.

\section{ORCID iDs}

Igor Grabovac http://orcid.org/0000-0001-9605-1467

Guillermo F López Sánchez http://orcid.org/0000-0002-9897-5273

\section{REFERENCES}

1 Radford J Key findings about U.S. immigrants. Available https://www. pewresearch. org/fact-tank/2019/06/17/key-findings-about-u-s-immigrants/ (accessed 5 Jan 2020).

2 Bourque F, van der Ven E, Malla A. A meta-analysis of the risk for psychotic disorders among first- and second-generation immigrants. Psychol Med 2011;41:897-910.
3 Mindlis I, Boffetta P. Mood disorders in first- and second-generation immigrants: systematic review and meta-analysis. Br J Psychiatry 2017;210:182-9.

4 Falah-Hassani K, Shiri R, Vigod S, et al. Prevalence of postpartum depression among immigrant women: a systematic review and meta-analysis. J Psychiatr Res 2015;70:67-82.

5 Guillot M, Gavrilova N, Pudrovska T. Understanding the "Russian mortality paradox" in Central Asia: evidence from Kyrgyzstan. Demography 2011;48:1081-104.

6 Popham F, Boyle PJ. Is there a 'Scottish effect' for mortality? Prospective observational study of census linkage studies. J Public Health (Oxf.) 2011;33:453-8.

7 Wang Q, Lysenko T. Immigrant underemployment across US metropolitan areas: from a spatial perspective. Urban Studies 2014;51:2202-18.

8 Williams DR, Priest N, Anderson NB. Understanding associations among race, socioeconomic status, and health: patterns and prospects. Health Psychol 2016;35:407-11.

9 Vacková J, Brabcová I. Socioeconomic status and health of immigrants. Neuro Endocrinol Lett 2015;36:69-77.

10 Hovanec J, Siemiatycki J, Conway DI, et al. Lung cancer and socioeconomic status in a pooled analysis of case-control studies. PLoS One 2018;13:e0192999.

11 Zeng X, Liu J, Tao S, et al. Associations between socioeconomic status and chronic kidney disease: a meta-analysis. I Epidemiol Community Health 2018;72:270-9.

12 Braudt DB, Lawrence EM, Tilstra AM, et al. Family socioeconomic status and early life mortality risk in the United States. Matern Child Health J 2019;23:1382-91.

13 Shor E, Roelfs D, Vang ZM. The "Hispanic mortality paradox" revisited: meta-analysis and meta-regression of life-course differentials in Latin American and Caribbean immigrants' mortality. Soc Sci Med 2017;186:20-33.

14 Le-Scherban F, Albrecht SS, Bertoni A, et al. Immigrant status and cardiovascular risk over time: results from the Multi-Ethnic Study of Atherosclerosis. Ann Epidemiol 2016;26:429-35.

15 Kakinami L, Wissa R, Khan R, et al. The association between income and leisure-time physical activity is moderated by utilitarian lifestyles: a nationally representative US population (NHANES 1999-2014). Prev Med 2018;113:147-52.

16 Warburton DER, Bredin SSD. Health benefits of physical activity: a systematic review of current systematic reviews. Curr Opin Cardiol 2017;32:541-56.

17 de Rezende LF, Rodrigues Lopes M, Rey-Lopez JP, et al. Sedentary behavior and health outcomes: an overview of systematic reviews. PLOS One 2014;9:e105620.

18 Hallal PC, Andersen LB, Bull FC, et al. Global physical activity levels: surveillance progress, pitfalls, and prospects. Lancet 2012;380:247-57.

19 Guthold R, Stevens GA, Riley LM, et al. Worldwide trends in insufficient physical activity from 2001 to 2016: a pooled analysis of 358 population-based surveys with 1.9 million participants. Lancet Glob Health 2018; 6:e1077-e1086-.

20 Yang L, Cao C, Kantor ED, et al. Trends in sedentary behavior among the US population, 2001-2016. JAMA 2019;321:1587-97.

21 Liu SY, Lu L, Pringle D, et al. Impact of immigration status on health behaviors and perceptions in cancer survivors. Cancer Med 2019;8:2623-35.

22 Tremblay MS, Bryan SN, Perez CE, et al. Physical activity and immigrant status: evidence from the Canadian Community Health Survey. Can J Public Health 2006;97:277-82.

23 Dogra S, Meisner BA, Ardern Cl. Variation in mode of physical activity by ethnicity and time since immigration: a cross-sectional analysis. Int I Behav Nutr Phys Act 2010;7:75

24 Petry NM. A comparison of young, middle-aged, and older adult treatment-seeking pathological gamblers. Gerontologist 2002;42:92-9.

25 Armstrong T, Bull F. Development of the world health organization global physical activity questionnaire (GPAQ). J Public Health 2006;14:66-70.

26 Tremblay MS, LeBlanc AG, Kho ME, et al. Systematic review of sedentary behaviour and health indicators in school-aged children and youth. Int I Behav Nutr Phys Act 2011;8:98.

27 Sisson SB, Church TS, Martin CK, et al. Profiles of sedentary behavior in children and adolescents: the US National Health and Nutrition Examination Survey, 2001-2006. Int J Pediatr Obes 2009:4:353-9.

28 Choi J, Lee M, Lee JK, et al. Correlates associated with participation in physical activity among adults: a systematic review of reviews and update. BMC Public Health 2017:17:356.

29 Abula K, Gropel P, Chen K, et al. Does knowledge of physical activity recommendations increase physical activity among Chinese college students? Empirical investigations based on the transtheoretical model. J Sport Health Sci 2018;7:77-82.

30 Taylor RJ, Forsythe-Brown I, Mouzon DM, et al. Prevalence and correlates of everyday discrimination among black Caribbeans in the United States: the impact of nativity and country of origin. Ethnic Health 2019;24:463-83.

31 Deelen I, Ettema D, Dijst M. Too busy or too far away? The importance of subjective constraints and spatial factors for sports frequency. Managing Sport Leisure 2016;21:239-64 .

32 Portes A, Light D, Fernandez-Kelly P. The U.S. Health System and Immigration: an Institutional Interpretation. Sociol Forum (Randolph N J) 2009;24:487-514.

33 National Equity Atlas. Car access United States. Available https://nationalequityatlas. org/indicators/Car_access 
34 Occupations of unauthorized immigrant workers. Available https://www.pewresearch. org/hispanic/2016/11/03/occupations-of-unauthorized-immigrant-workers/ (accessed 31 Mar 2020).

35 OECD. Immigrant background, student performance and students' attitudes towards science. In: PISA 2015 Results. Vol. I. Paris: OECD Publishing, 2016.

36 Palloni A, Arias E. Paradox lost: explaining the Hispanic adult mortality advantage. Demography 2004;41:385-415.
37 Stirbu I, Kunst $A E$, Bos V, et al. Differences in avoidable mortality between migrants and the native Dutch in The Netherlands. BMC Public Health 2006;6:78.

38 Ku PW, Steptoe A, Liao Y, et al. A cut-off of daily sedentary time and all-cause mortality in adults: a meta-regression analysis involving more than 1 million participants. $B M C$ Med 2018;16:74. 